\title{
Capgras-like syndrome in a patient with an acute urinary tract infection
}

\author{
This article was published in the following Dove Press journal: \\ Neuropsychiatric Disease and Treatment \\ 16 January 2013 \\ Number of times this article has been viewed
}

\section{Massimo Salviati \\ Francesco Saverio Bersani \\ Francesco Macrì \\ Marta Fojanesi \\ Amedeo Minichino \\ Mariana Gallo \\ Francesco De Michele \\ Roberto Delle Chiaie \\ Massimo Biondi}

Department of Neurology and

Psychiatry, Sapienza University

of Rome, Rome, Italy
Correspondence: Francesco Saverio

Bersani

Department of Neurology and

Psychiatry, Sapienza University

of Rome, Viale dell'Università 30,

00185 , Rome, Italy

$\mathrm{Tel}+393405165865$

Fax+3906 4991 4728

Email bersani.fs@tiscali.it

\begin{abstract}
Delusional misidentification syndromes are a group of delusional phenomena in which patients misidentify familiar persons, objects, or themselves, believing that they have been replaced or transformed. In $25 \%-40 \%$ of cases, misidentification syndromes have been reported in association with organic illness. We report an acute episode of Capgras-like delusion lasting 8 days, focused on the idea that people were robots with human bodies, in association with an acute urinary infection. To our knowledge, this is the first case report associating urinary tract infection with Capgras-like syndrome. Awareness of the prevalence of delusional misidentification syndromes associated with acute medical illness should promote diligence on the part of clinicians in recognizing this disorder.
\end{abstract}

Keywords: delusional misidentification, Capgras syndrome, urinary tract infection, psychosis

\section{Introduction}

Delusional misidentification syndromes are a group of delusional phenomena in which patients misidentify familiar persons, objects, or themselves, believing that they have been replaced or transformed. These syndromes can be considered delusional because the misidentifications are false and are not correctable by experience or reason. ${ }^{1}$

The most common form of misidentification is the Capgras syndrome. Originally described by Capgras and Reboul-Lachaux, ${ }^{2,3}$ this disorder consists of the delusional belief that a person or persons have been replaced by "doubles" or impostors. Following 19th century reports in Germany by Kahlbaum, ${ }^{4}$ Capgras and Reboul-Lachaux described "Mme M", who displayed a florid set of psychotic symptoms, including the belief that her husband, children, neighbors, and others had been replaced by doubles. The doubles themselves were replaced by other doubles ( 80 times in the case of her husband). However, patients with the delusion usually report that people emotionally close to them have been substituted. Often they hold this belief with frightening conviction, even being prepared to kill the "impostor". ${ }^{5}$ Cases have also been described where the delusion is that pets ${ }^{6,7}$ or even inanimate objects ${ }^{8}$ have been replaced by replicas. ${ }^{9}$

A recent well publicized UK court case of Capgras delusion involved a teacher named Alan Davies who, following a car crash, developed the belief that his wife had died in the accident and that the woman living with him was an impostor, and someone with whom he had become uncomfortable. He still insists that his real wife died in the accident, and he successfully sued the driver of the other vehicle for the 
distress caused. In court, a consultant psychiatrist explained that Mr Davies was suffering from Capgras delusion. ${ }^{9,10}$

Another type of misidentification is the Fregoli syndrome, ${ }^{11}$ in which there is the belief that a person who is well known to the patient is actually pretending to take on the appearance of a relative stranger whom the patient encounters. Vie characterized Capgras syndrome as the illusion of negative doubles and Fregoli syndrome as the illusion of positive doubles. ${ }^{12}$

Other misidentification syndromes are the syndrome of intermetamorphosis, characterized by the belief that another person has changed both his physical and psychological identities (ie, has been transformed into another) and the syndrome of subjective doubles, characterized by the belief that another person has been physically transformed into the patient's own self. ${ }^{1}$

Misidentification syndromes are more frequent in females (75\%). The age of onset varies from 12 to 78 years, with an average in the early $40 \mathrm{~s} .{ }^{13}$ In more than four of five patients, the onset is after the age of 30 years. ${ }^{14}$ Capgras delusion occurs in a variety of settings as a symptom of idiopathic psychiatric illness, eg, schizophrenia or mood disorders, and in $25 \%-40 \%$ of cases misidentification syndromes have been reported in association with organic illnesses, including cerebrovascular disease, post-traumatic encephalopathy, temporal lobe epilepsy, post-encephalitic parkinsonism, infections, viral encephalitis, migraine, vitamin B12 deficiency, hepatic encephalopathy, hypothyroidism, pseudoparathyroidism, and dementia. ${ }^{15}$

Some studies have found correlations between the psychopathological symptoms of Capgras syndrome (in particular, misidentification and alterations of memory, feeling of familiarity, monitoring of self, and reality) and neurobiological alterations and damage to the right temporal lobe, and the limbic and bifrontal regions. ${ }^{16,17}$ Other studies, in which functional magnetic resonance imaging was used, emphasize the importance of the superior temporal sulcus in face recognition and perception, and show that alteration of this specific area could compromise these functions. ${ }^{18}$ Ellis and Young have also suggested that, despite their obvious differences, there might be a link between prosopagnosia (complete inability to recognize previously familiar faces) and Capgras delusion, positing the idea that the two conditions might be mirror images of one another. ${ }^{19}$ Here we describe the case of a young patient with an acute episode of Capgras syndrome lasting for 8 days in association with an acute urinary tract infection.

\section{Case report}

Mr J was an 18-year-old academically gifted South American student who was visiting Italy as a tourist. He had normal neuropsychological development during infancy. He was travelling around Europe during his holidays to celebrate the end of high school. He was an easy-going person, having had many relationships but without a significant long-term partner. He had several hobbies (football, technologies, cars) and planned to start his university studies in international politics. He had not experienced any previous psychopathological problems. He did not drink alcohol or caffeine, and did not use any illicit or recreational drugs. His great-grandmother had suffered from schizophrenia.

The patient was admitted to the psychiatric ward of Policlinico Umberto I Hospital, Sapienza University of Rome, appearing to be deeply distressed, dysphoric, and confused, with disorganized speech and thoughts. He presented with persecutory and transformation delusions focused on the idea that every person was a robot with a human body. He had disorganized auditory hallucinations, hearing voices of relatives (mother, father, cousins) telling him to escape from the hospital because there were robots there who wanted to kill him. He did not recognize his cousin (thinking that the cousin was a robot with the body and face of his cousin). A toxicology screen was negative for psychoactive substances.

Computed tomography of the head without contrast did not show any hemorrhagic intraparenchymal or extraparenchymal lesions or alterations in parenchymal density, either over and under the cerebellar tentorium, and showed normal flow in the ventricular system and cerebral spinal fluid spaces. Blood laboratory investigations were normal, with the exception of white blood cells at 11,650 per $\mu \mathrm{L}$ and neutrophils at 7950 per $\mu \mathrm{L}$.

On admission, the patient was started on clonazepam $5 \mathrm{mg} /$ day to treat his agitation, risperidone $4 \mathrm{mg} /$ day to treat his psychotic symptoms, and valproate $750 \mathrm{mg}$ /day to treat his dysphoric mood.

On day 3 , the patient presented again with fever $\left(38.5^{\circ} \mathrm{C}\right)$ and a worsening of his delusional symptoms. His hallucinations had worsened in intensity and frequency. He was distressed, presenting with psychomotor agitation and disorganized behavior, and tried to escape from the ward. Blood tests were again normal, with the exception of white blood cells at 16,790 per $\mu \mathrm{L}$, neutrophils at 14,440 per $\mu \mathrm{L}$ (86\%), and lymphocytes of 7.4\%. Microscopic examination of the urinary sediment showed many white blood cells, red blood cells, and bacteria. Urine culture was positive for Proteus mirabilis ( $>100,000$ colony-forming units) and Enterococcus spp ( $<1000$ colony-forming units). Treatment with ciprofloxacin was started at $1000 \mathrm{mg}$ /day. The fever disappeared on day 7 , and his psychopathological 
condition improved. Laboratory blood investigations also improved, with a normal white cell count of 6.330 per $\mu \mathrm{L}$, neutrophils at 3680 per $\mu \mathrm{L}(58.2 \%)$ and lymphocytes at $25.4 \%$. By day 8 , the delusional and hallucination symptoms had disappeared, the patient was cooperative and well orientated in time and space, and he presented with euthymic mood and normal psychomotor skills. He remembered the hallucinations and delusions as if they had been a dream he had had whilst awake, with qualitative alteration of consciousness. On the same day, because of full remission of symptoms, the patient was discharged from hospital and returned to Brazil accompanied by relatives.

\section{Discussion}

Capgras delusions are typically focused on a small number of people or just one person. These people are typically emotionally close to the deluded person; atypically, Mr J believed that every person was a robot, even people he did not know very well, including doctors and nurses. Because of this particular clinical feature, we would define his psychopathological condition as Capgras-like syndrome. The clinical report presented here clearly suggests a correlation between an acute infection and delusional symptoms, and to our knowledge, this is the first case report of an association between urinary tract infection and Capgras-like syndrome.

Several psychopathological areas are usually impaired in Capgras syndrome and in this case impaired consciousness, thoughts, memory, perception, and allopsychic derealization were involved. We can argue that such a complex symptomatology could indicate diffuse functional damage of the brain. For this reason, it is possible to hypothesize that the frequent association between organic disease and misidentification delusions is linked to wider neuronal interconnectivity (hodological) problems rather than to specific topological problems.

Even if delusional misidentifications are known to be potentially correlated with infectious conditions, few relevant papers are available in the scientific literature. Crichton and Lewis reported on a patient with acquired immune deficiency syndrome who developed Capgras syndrome as part of an acute confusional state resulting from an opportunistic infection. ${ }^{20}$ In 1991, Förstl et al reviewed 260 case reports of misidentification syndromes, ${ }^{21}$ and identified two cases in association with pneumonia, one case in association with tuberculosis, one case in association with acquired immune deficiency syndrome, and one case in association with neurocysticercosis.

It is also true that several other infective conditions may exacerbate or lead to different kinds of acute psychosis.
Infections caused by Epstein-Barr virus, ${ }^{22}$ Borrelia, ${ }^{23}$ human immunodeficiency virus, ${ }^{24}$ Mycoplasma pneumoniae, ${ }^{25}$ Coxiella Burnetii, ${ }^{26}$ toxoplasmosis, ${ }^{27}$ herpes simplex, ${ }^{28}$ and Salmonella typhi ${ }^{29}$ have been reported as possible causes of acute psychosis.

In cases of infective diseases with secondary sepsis, there may be two different pathological mechanisms related to brain injury. On the one hand, we could have an injury related to the inflammatory system, including proinflammatory cytokines, and in particular tumor necrosis factor alpha. This mediator could involve direct cellular damage to the brain, mitochondrial and endothelial dysfunction, and disturbances in neurotransmission. ${ }^{30}$ On the other hand, we may have a direct interaction between the proinflammatory system and cholinergic transmission that produces confusion directly. ${ }^{31}$ Environmental agents, such as stress or bacteria, are unlikely to be sufficient to induce a delusional syndrome; in the case of $\mathrm{Mr} \mathrm{J}$, a vulnerability to psychosis was identified in the family history, ie, his greatgrandmother being affected by schizophrenia.

An interesting feature of this case is the theme of robots. To date, only one paper has reported robots or androids as possible misidentifications occurring in Capgras syndrome. ${ }^{9}$ This may be related to the fact that only in the last few years has the presence of robots with human features become culturally and internationally relevant (for example with the "Blade Runner" film and the books written by Isaac Asimov). It is possible that the contents of misidentification delusions are changing (humans become androids) concomitantly with general cultural issues of the day, and that other terms should probably be used to describe this emerging psychopathological syndrome, eg, "android syndrome".

It is often difficult to distinguish between psychosis due to organic conditions and psychosis heralding the onset of a chronic psychotic illness, in particular when there is a positive family history of schizophrenia (as in the case of $\mathrm{Mr} \mathrm{J}$ ) and when different kind of medications are given concomitantly, like the antipsychotics and antibiotics in the present case.

In the future, it would be extremely valuable to perform functional magnetic resonance imaging to investigate delusional misidentification syndromes further. Awareness of the prevalence of delusional misidentification syndromes associated with acute medical illness should promote diligence on the part of clinicians in recognizing this disorder. Organic disease should be ruled out before a diagnosis of a mental or cognitive disorder is made.

\section{Disclosure}

The authors report no conflicts of interest in this work. 


\section{References}

1. Jocic Z. Delusional misidentification syndromes. Jefferson Journal of Psychiatry. 1992;10:4.

2. Capgras J, Reboul-Lachaux J. L'illusion des sosies dans un delire systematise chronique. Bull Soc Clin Med Ment. 1923;11:6-16. French.

3. Ellis HD, Whitley J, Luauté JP. Delusional misidentification: the three original papers on Capgras, Frégoli and intermetamorphosis delusions (Classic Text No 17). Hist Psychiatry. 1994;5:117-146.

4. Mojtabai R. Misidentification phenomena in German psychiatry: a historical review and comparison with French/English approach. Hist Psychiatry. 1996;7:137-158.

5. Silva JA, Leong GB, Garza-Treviño ES, et al. A cognitive model of dangerous delusional misidentification syndromes. J Forensic Sci. 1994;39:1455-1467.

6. Reid I, Young AW, Hellawell DJ, et al. Voice recognition impairment in a blind Capgras patient. Behav Neurosci. 1993;6:225-228.

7. Wright B, Mindham R, Burn W, et al. Canine Capgras. Irish J Psychol Med. 1994;11:31-33.

8. Andersen DN. The delusion of inanimate doubles, implications for understanding the Capgras delusion. Br J Psychiatry. 1988;153:694-699.

9. Ellis HD, Lewis MB. Capgras delusion: a window on face recognition. Trends Cogn Sci. 2001;5:149-156.

10. Gentleman A. Car crash victim wins $£ 130,000$ for 'impostor' wife. The Guardian. 1999, March 5. Available at http://www.guardian.co.uk/ uk/1999/mar/05/ameliagentleman.

11. Courbon P, Fail G. Syndrome “d'illusion de Fregoli” et schizophrenie. Ann Med Psychol (Paris). 1927;85:289-290. French.

12. Vie J. Un trouble de l'identification des personnes: L'illusion des sosies. Ann Med Psychol (Paris). 1930;88:214-237. French.

13. Berson RJ. Capgras's syndrome. Am J Psychiatry. 1983;140:969-978.

14. Enoch MD. Whose double? In: Christodoulou GN, editor. The Delusional Misidentification Syndromes. Basel, Switzerland: Karger; 1986.

15. Feinberg TE, Roane DM. Delusional misidentification. Psychiatr Clin North Am. 2005;28:665-683.

16. Signer SF. Capgras' syndrome: the delusion of substitution. J Clin Psychiatry. 1987;48:147-150.

17. Hillers Rodríguez R, Madoz-Gúrpide A, Tirapu Ustárroz J. Capgras syndrome: a proposal of neuropsychological battery for assessment. Rev Esp Geriatr Gerontol. 2011;46:275-280. Spanish.
18. Iidaka $\mathrm{T}$. The role of the superior temporal sulcus in face recognition and perception. Brain Nerve. 2012;64:737-742. Japanese.

19. Ellis HD, Young AW. Accounting for delusional misidentifications. $\mathrm{Br}$ J Psychiatry. 1990;157:239-248.

20. Crichton $P$, Lewis S. Delusional misidentification, AIDS and the right hemisphere. Br J Psychiatry. 1990;157:608-610.

21. Förstl H, Almeida OP, Owen AM, Burns A, Howard R. Psychiatric, neurological and medical aspects of misidentification syndromes: a review of 260 cases. Psychol Med. 1991;21:905-910.

22. Jarvis MR, Wasserman AL, Todd RD. Acute psychosis in a patient with Epstein-Barr virus infection. J Am Acad Child Adolesc Psychiatry. 1990;29:468-469.

23. Csaszar T, Patakfalvi A. Differential diagnostic problems in Lyme disease (Borrelia infection resulting in acute exogenous psychosis). Orv Hetil. 1994;135:2269-2271. Hungarian.

24. Halstead S, Riccio M, Harlow P, Oretti R, Thompson C. Psychosis associated with HIV infection. Br J Psychiatry. 1988;153:618-623.

25. Moor S, Skrine H. Psychosis in mycoplasma infection. Postgrad Med J. 1989;65:96-97.

26. Gerdes LU, Nielsen HK. Q fever with acute paranoid psychosis. Ugeskr Laeger. 1989;147:1412-1413. Danish.

27. Zhu S. Psychosis may be associated with toxoplasmosis. Med Hypotheses. 2009;73:799-801

28. Yolken R. Viruses and schizophrenia: a focus on herpes simplex virus. Herpes. 2004;11 Suppl 2:83A-88A.

29. Muhangi JR. Functional or organic psychosis. (Four cases of typhoid fever initially presenting as various forms of psychiatric disorder.) Afr J Med Sci. 1972;3:319-326.

30. Zampieri FG, Park M, Machado FS, Azevedo LC. Sepsis-associated encephalopathy: not just delirium. Clinics (Sao Paulo). 2011;66: 1825-1831.

31. Cerejeira J, Nogueira V, Luís P, Vaz-Serra A, Mukaetova-Ladinska EB. The cholinergic system and inflammation: common pathways in delirium pathophysiology. J Am Geriatr Soc. 2012;60:669-675.
Neuropsychiatric Disease and Treatment

\section{Publish your work in this journal}

Neuropsychiatric Disease and Treatment is an international, peerreviewed journal of clinical therapeutics and pharmacology focusing on concise rapid reporting of clinical or pre-clinical studies on a range of neuropsychiatric and neurological disorders. This journal is indexed on PubMed Central, the 'PsycINFO' database and CAS.

\section{Dovepress}

The manuscript management system is completely online and includes a very quick and fair peer-review system, which is all easy to use. Visit http://www.dovepress.com/testimonials.php to read real quotes from published authors. 